\title{
PRIMARY LATERAL SCLEROSIS
}

\author{
A CASE REPORT WITH SPECT STUDY
}

\author{
WALTER OLESCHKO ARRUDA*, MAURICIO COELHO NETO**
}

\begin{abstract}
Primary lateral sclerosis (PLS) is a neurodegenerative disease with progressive corticospinal involvement and characterized by lower limbs spasticity followed by upper limbs involvement, rare cranial nerve involvement, typical sparing of all sensory modalities, sphincteric function and eventually mild cognitive changes. The authors report a case of PLS in a 43-year-old woman with 3 years of clinical follow-up and extensive laboratory investigation, including a SPECT study which disclosed bilateral frontal motor area hypometabolism. Several aspects about this unique disease were reviewed, including differential diagnosis with other more common neurological disorders.
\end{abstract}

KEY WORDS: primary lateral sclerosis, spastic paraparesis, MRI, SPECT.

\section{Esclerose lateral primária: relato de caso com estudo por SPECT}

RESUMO - Esclerose lateral primária (ELP) é forma rara de doença neurodegenerativa de origem desconhecida caracterizada por envolvimento progressivo do trato corticoespinhal, traduzido clinicamente como quadro de espasticidade progressiva, inicialmente nos membros inferiores, com hiperreflexia e outros sinais piramidais. Notoriamente há preservação de todas as modalidades de sensibilidade e função esfincteriana. Discretos achados de disfunção cognitiva frontal podem ser eventualmente encontrados. Os autores relatam um caso de ELP em uma mulher de 43 anos, com seguimento clínico por 3 anos e com extensa avaliação complementar laboratorial. Estudo de SPECT revelou áreas bilaterais de hipometabolismo nas regiões frontais, córtex motor. Vários aspectos relacionados a esta rara entidade são discutidos, principalmente seu diagnóstico diferencial com outras doenças neurológicas mais comuns. SPECT

PALAVRAS-CHAVE: esclerose lateral primária, paraparesia espástica, ressonância nuclear magnética,

Primary lateral sclerosis (PLS) was first described by Charcot in 1865, and since its first clinical and neuropathological description controversy still continues over the existence of PLS as a nosologic entity ${ }^{1-3}$. Actually, it was Erb, in 1875, who proposed the term PLS for the first time. The disease has been proposed to be an atypical clinical presentation of already known diseases such as amyotrophic lateral sclerosis (ALS) ${ }^{4}$, frontal dementia ${ }^{2}$, Lewy's bodies disease ${ }^{5}$ or multiple sclerosis. Nevertheless, the development of neuropathologic techniques and complementary investigation (structural and functional neuroimage, neurophysiological tests) and the accumulating descriptions of similar cases, have buttressed the concept of PLS as a separate disease entity. In spite of this, the diagnosis is usually made after the exclusion of other diseases with similar clinical spectrum. Thus, the diagnosis of PLS is based on a careful clinical and laboratory investigation and an adequate follow-up. The etiology of PLS is not yet clear, due to the rare incidence of the disease. A few cases

Unidade de Ciências Neurológicas, Hospital das Nações / Hospital Vita: *Neurologist; **Neurosurgery Resident. Aceite: 18-março-1998.

Dr. Walter O. Arruda - Rua Raphael Papa 10 - 80530-190 Curitiba PR - Brasil. FAX 55412641238. 
of PLS presenting as paraneoplastic syndrome, secondary to breast cancer, have been reported ${ }^{6}$. A genetic trait has not been identified yet but one family with three affected brothers with PLS has already been reported ${ }^{7}$. Our report reveals our experience in one case of PLS and reviews some features of this unique entity.

\section{CASE REPORT}

A 43-year-old woman, with a negative family history for neurological diseases, showed progressive gait difficulty. She had neither other associated symptoms, such as pain, weakness and cramps, nor sensory complaints. Control of sphincters was normal and no upper extremities changes were refered. Her past medical history was unremarkable except for a diagnosis of hypothyroidism with adequate hormone replacement.

Mental status and cranial nerves examination were normal. Physical examination was normal and neurological examination showed normal upper limbs muscle strength, normal tonus, normal deep tendon reflexes in the right arm and increased left arm reflexes and positive left Hoffmann's sign. Lower extremities were spastic, with normal muscle strength muscle, increased deep reflexes, with left ankle clonus, and bilateral plantar cutaneous reflex in extension. All sensory modalities were normal. Her balance and coordination were normal. A spastic gait could be noticed, though she could walk without support. There was no evidence of muscle atrophy and fasciculations.

Laboratory tests including cerebrospinal fluid (CSF) examination (including protein electrophoresis and immunologic tests for HTLV-I and II) routine tests (blood count, ESR, electrolytes, glucose, creatinine, T3, T4, TSH, vitamin B12), blood serological tests (VDRL, HIV, Lyme disease), serum lead, copper, zinc, EEG, EEG brain-mapping, four limbs electromyography/nerve conduction studies (EMG/NC), MRI of all spinal segments, evoked potentials (VEP, BAEP, legs SSEP). Some of these tests (e.g. EMG/NC, CSF, MRI) were repeated more than once during her 3 years follow-up. All were normal or negative, except SSEP which presented decreased central conduction velocities.

Brain MRI showed a moderate atrophy of the bilateral pre-frontal areas, corresponding to motor frontal areas involvement (Fig 1) Brain SPECT (technetium HMPAO) disclosed a decreased glucose metabolism in the same frontal areas (Fig 2).

The diagnosis of PLS was established after exclusion of other possible diagnoses. The use of bacoflen provided no clinical improvement even with high doses of $120 \mathrm{mg}$ per day. During three years of follow up, her gait gradually worsened and now she needs a cane for walking. Her speech became dysarthric and upper extremities spasticity was noticed over the last 6 months.

\section{DISCUSSION}

PLS is characterized by a progressive spasticity of lower extremities in the majority of cases, but in some cases upper extremities are affected first ${ }^{1,8}$. Deep and superficial hyperreflexia is present. Sensory modalities (deep and superficial) and sphincteric control are characteristically spared; fasciculation is not present and muscle bulk is preserved. The course of disease is slow, speech may become increasingly dysarthric, and ascending involvement of arms is usually observed in later stages. Rare forms may present bulbar involvement at the onset ${ }^{3}$. The average age at onset is 40 to 50 years, although children's cases have been reported ${ }^{8,9}$. Cognitive deficits are moderate ${ }^{2}$, and mild alterations may be detected by adequate neuropsychological testing. Neuropsychometric tests may be eventually useful to detect cortical function abnormalities in cases where paraparesis and spinal cord compression by cervical spondylopathy, an incidental common finding in some patients, are both present. The disease has a progressive course, with corticospinal dysfunction at the beginning with later corticobulbar involvement (pathologic laughter and crying, and central facial nerve palsy).

Two distinct forms of initial clinical presentation may be identified: 1. chronic progressive paraparesis and tetraparesis, with initial involvement of spinal cord; 2. chronic cortico-bulbar and spinobulbar form, with predominant bulbar involvement. Both forms have motor cortex involvement, which is the hallmark of the disease. Mill's syndrome, ascending or descending progressive hemiplegia, may be considered an uncommon form of $\mathrm{PLS}^{10}$. Pathological findings have been common for both clinical forms of presentation. The main alteration found was the loss of neurons (Betz 


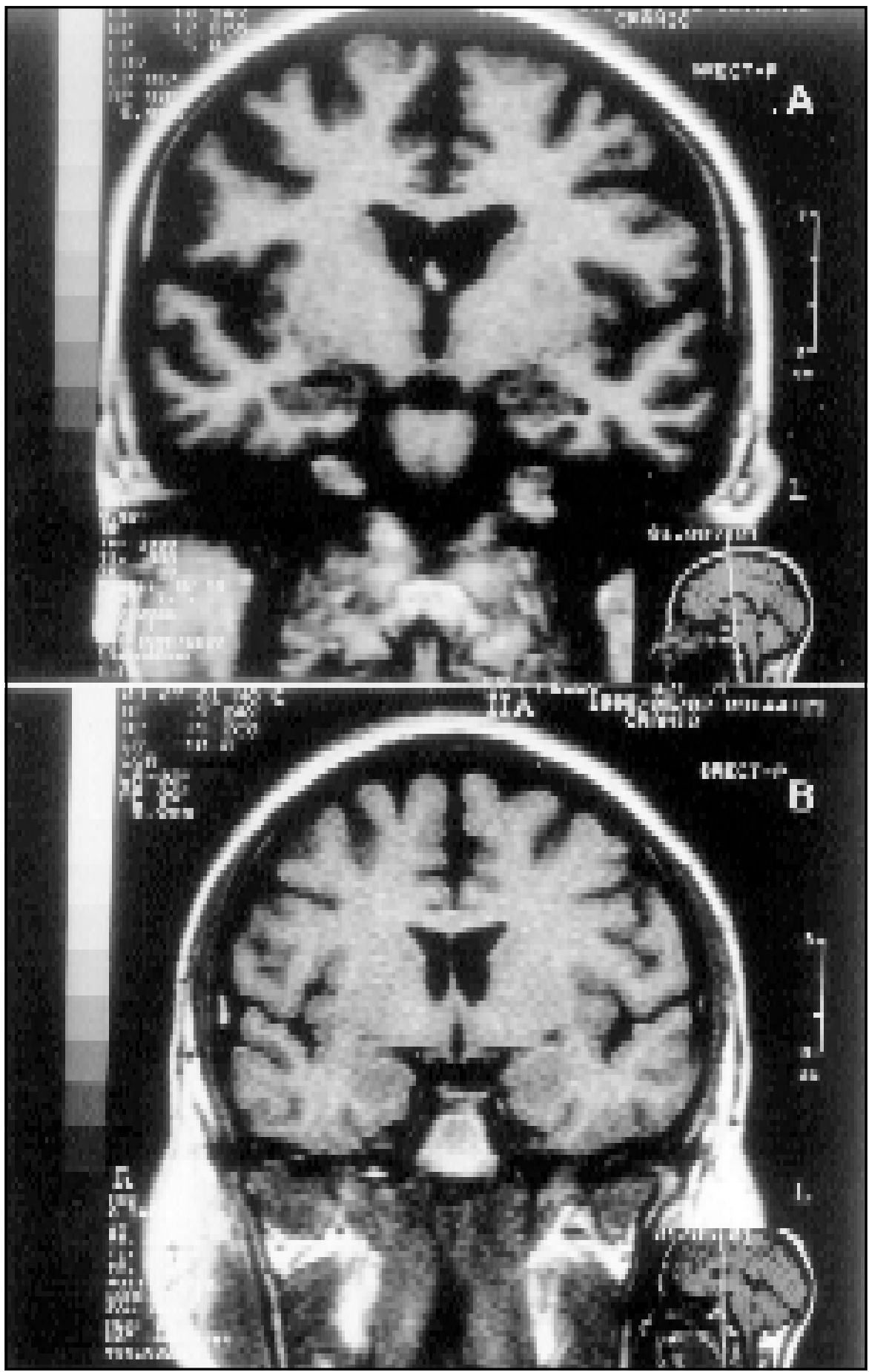

Fig 1. A - Patient's MRI, coronal T1-weighted section, shows marked bilateral sulci widening involving both frontal lobes; B - Age and sex-matched MRI control, T1-weighted coronal section. 


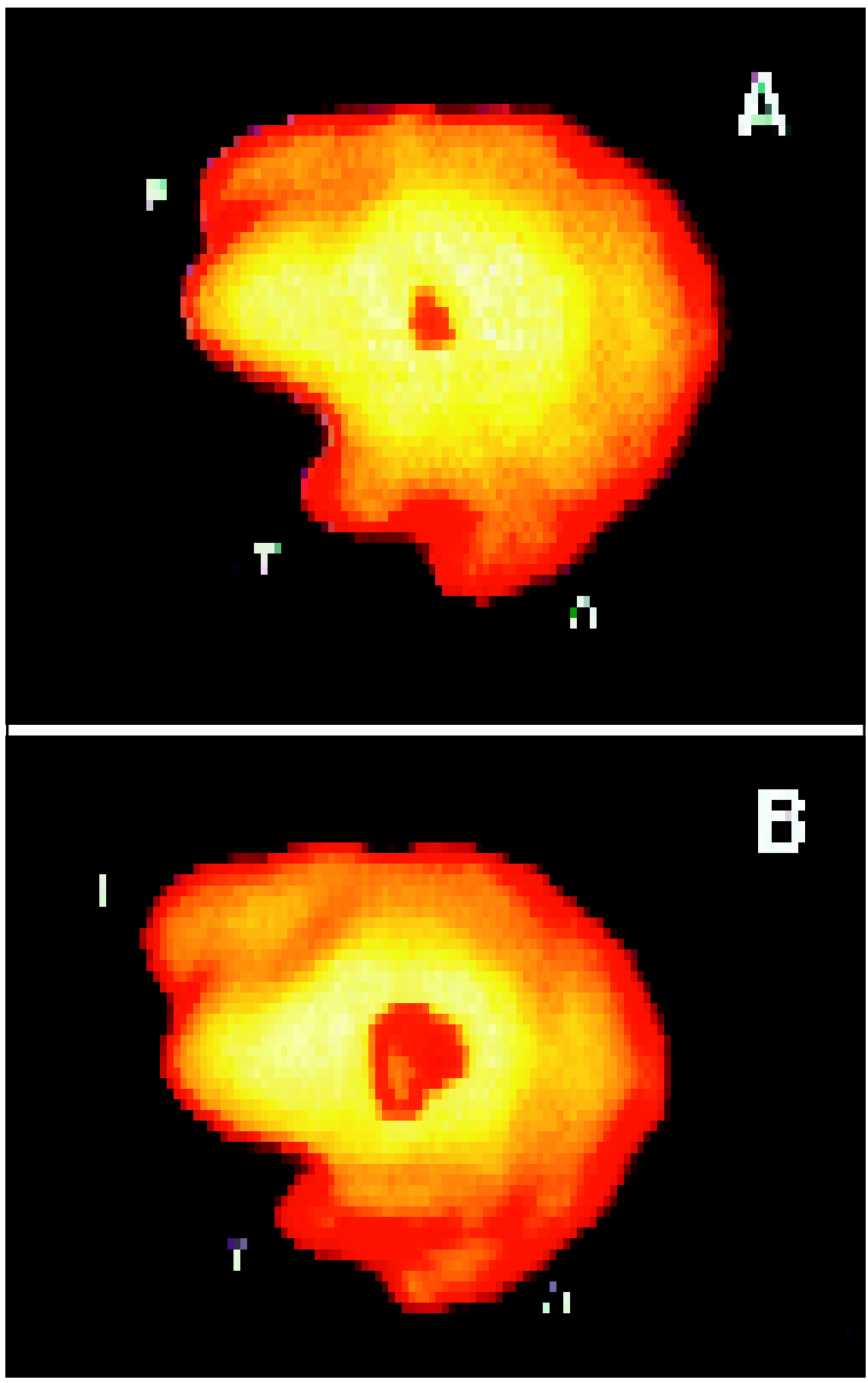

Fig 2. (A) right and (B) left lateral views of HMPAO-Tc SPECT disclose marked hypometabolic areas (darkened red), more evident at the left side, corresponding to frontal motor cortex. F - frontal pole; $O$ - occipital pole; $T$ - temporal apex. 
cells, pyramidal cells longer than $50 \mu \mathrm{m}$ ) in levels 3 and 5 of the cortex of the precentral gyrus, degeneration of the corticospinal pathways, with preservation of neurons of the anterior horn of the spinal cord ${ }^{1,10}$. Some authors have compared the findings to ALS controls, and observed a more representative loss of neurons in PLS ${ }^{1}$. In some cases the findings of the loss of cortical neurons and corticospinal tract degeneration could be identified through image examination ${ }^{2,11}$.

Our patient fullfilled all clinical and laboratory criteria proposed by Pringle et al. ${ }^{1}$ (Table 1).

MRI is an important tool to exclude other diseases (Table 2) and may show some suggestive findings corresponding to the loss of pyramidal cortical Betz cells in the precentral gyrus of motor area. Area atrophy may be usually found at later stages of the disease. Thus, early investigations may result as normal. Pringle et al. ${ }^{1}$ reported precentral gyrus atrophy in 6 out of 8 cases studied, but the period of disease evolution when the examination was performed was not reported. Atrophy and central sulcus widening are statistically significant when compared with ALS and dementia controls. Caselli et al. ${ }^{2}$ identified atrophy in 2 out of 9 patients. Gastaut et al. ${ }^{3}$ found moderate atrophy in 2 out of 5 cases of PLS with MRI examinations. The remaining 3 presented normal examination.

Our patient presents moderate bilateral brain atrophy in the fronto temporal region with enlargement of Sylvian fissure, when compared with normal control of the same age (Fig 1). This feature was already identified at the beginning of her disease, and at her last MRI examination after 3 years of follow up.

There are few reports of SPECT studies in PLS. Caselli et al. ${ }^{2}$ performed this examination in 6 out of 9 patients. All patients presented hypometabolism in the posterior frontal region, including two patients with pericentral atrophy at MRI.

Table 1. Diagnostic criteria for PLS proposed by Pringle et al. ${ }^{1}$.

\section{Clinical}

1. Insidious onset of spastic paresis, usually beginning in lower extremities but occasionally bulbar or in an upper extremity.

2. Adult onset, usually fifth decade or later.

3. Absence of family history.

4. Gradually progressive course (i.e. not step-like).

5. Duration $\geq 3$ years.

6. Clinical findings limited to those usually associated with corticospinal dysfunction.

7. Symmetrical distribution, ultimately developing severe spastic spinobulbar paresis.

\section{Laboratory (help in exclusion of other diagnosis)}

1. Normal serum chemistry including normal vitamin $B_{12}$ levels.

2. Negative serologic testes for syphilis (in endemic areas, negative Lyme and HTLV-1 serology).

3. Normal CSF parameters, including absence of oligoclonal bands.

4. Absent denervation potential on EMG or at most, occasional fibrillation and increased insertional activity in a few muscles (late and minor).

5. Absence of compressive lesions of cervical spine or foramen magnum (spinal MRI scanning).

6. Absence of high signal lesions on MRI similar to those seen in MS.

\section{Additionally suggestive of PLS}

1. Preserved bladder function.

2. Absent or very prolonged latency on cortical motor evoked responses in the presence of normal peripheral stimulus-evoked maximum compound muscle action potentials.

3. Focal atrophy of precentral gyrus on MRI.

4. Decreased glucose consumption in pericentral region on PET scan. 
Table 2. Differential diagnosis for primary lateral sclerosis.

\begin{tabular}{|c|c|c|}
\hline Group & Disease & Examination \\
\hline \multirow[t]{8}{*}{ Myelopathies } & Cervical and lumbar spondyloarthrosis & MRI \\
\hline & Syringomielia & $\begin{array}{l}\text { MRI, clinical signs of sensitive } \\
\text { dissociation }\end{array}$ \\
\hline & Spinal cord neoplasms & MRI \\
\hline & Arnold-Chiari malformations/ & Cranio-cervical junction MRI; \\
\hline & Tethered cord syndrome & Conus medullaris MRI \\
\hline & $\begin{array}{l}\text { Infective diseases involving vertebrae } \\
\text { and/or spinal cord (tuberculosis, fungi, } \\
\text { epidural abscess, HIV, syphilis) }\end{array}$ & $\begin{array}{l}\text { MRI; CSF; generally subacute clinical } \\
\text { course }\end{array}$ \\
\hline & $\begin{array}{l}\text { Arachnoiditis (several etiologies e.g. } \\
\text { neural fibrosclerosis) }\end{array}$ & MRI; CSF; arachnoid biopsy \\
\hline & $\begin{array}{l}\text { Metabolic (vitamin B12, vitamin E } \\
\text { deficiency) }\end{array}$ & $\begin{array}{l}\text { Posterior cord clinical symptoms / } \\
\text { signs; respective serum dosage, }\end{array}$ \\
\hline \multirow[t]{3}{*}{ Degenerative diseases } & Amyotrophic lateral sclerosis & Clinical features; EMG \\
\hline & Multiple sclerosis & $\begin{array}{l}\text { MRI of brain and spine; CSF; evoked } \\
\text { potentials }\end{array}$ \\
\hline & Spinocerebellar ataxia & Genetic tests; family history \\
\hline Infectious diseases & Tropical spastic paraparesis & CSF (HTLV I/II serology) \\
\hline Paraneoplastic syndrome & Breast cancer & Clinical / pathological diagnosis \\
\hline \multirow[t]{4}{*}{ Miscellanea } & DOPA-responsive dystonia & Therapeutic trial \\
\hline & Abetalipoproteinemia & Lipoprotein electrophoresis \\
\hline & Mitochondrial disease & Muscle biopsy; MRI \\
\hline & Leukodystrophy & Inborn metabolic diseases screening \\
\hline
\end{tabular}

Spinal cord compression caused by spinal degenerative changes may lead to a clinical picture akim to PLS and/or may be present in cases of PLS. In these cases, SPECT changes may be helpful as a diagnostic tool and a therapeutic guideline. The finding of frontal ( pre-motor) hypoperfusion is not specific to PLS, but helps to confirm the focal cortical degeneration. In our case, the loss of cortical neurons was unequivocally corroborated by both MRI and SPECT findings.

In conclusion, PLS can be considered a nosologic entity since image examination, neurophysiological and neuropathological tests can confirm its existence. More important, it must be differentiated from other causes of progressive paraparesis, some of them treatable or with a much dismal prognosis (e.g. ALS). Some improvement may be reached with bacoflen or dantrolene, but the majority of patients do not present any improvement. Intratecal infusion of bacoflen may be a potential therapeutic alternative but its use has not been yet established. Supportive psychotherapy associated with physiotherapy and occupational therapy are advised for PLS patients. 


\section{REFERENCES}

1. Pringle CE, Hudson AJ, Monoz AJ, et al. Primary lateral sclerosis: clinical features, neuropathology and diagnostic criteria. Brain 1992;115:495-520.

2. Caselli RJ, Smith BE, Osborne D. Primary lateral sclerosis: a neuropsychological study. Neurology 1995;45:2005-2009.

3. Gastaut JL, Michle B, Figarella-Branger D, et al. Chronic progressive spinobulbar spasticity: a rare form of primary lateral sclerosis. Arch Neurol 1988;45:509-513.

4. Bruyn RPM, Koelman JHTM, Troost D, de Jong JMBV. Motor neuron disease (amyotrophic lateral sclerosis) arising from longstanding primary lateral sclerosis. J Neurol Neurosurg Psychiatry 1995;58:742-744.

5. Hainfellner JÁ, Pilz P, Lassmann H, et al. Diffuse Lewy body disease as substrate of primary lateral sclerosis. J Neurol 1995;242:59-63.

6. Forsyth PA, Dalmau J, Graus F, et al. Motor neuron syndromes in cancer patients. Ann Neurol 1997;41:722-730.

7. Lerman-SagieT, Filiano J, Smith DW, et al. Infantile onset of hereditary ascending spastic paralysis with bulbar involvement. J Child Neurol 1996;41:54-57.

8. Sotaniemi KA, Myllylä VV. Primary lateral sclerosis: a debated entity. Acta Neurol Scand 1985;71:334-336.

9. Grunnet ML, Leicher C, Zimmermann A, et al. Primary lateral sclerosis in a child. Neurology 1989;39:1530-1532.

10. Gastaut JL, Bartolomei F. Mill's syndrome: ascending (or descending ) progressive hemiplegia: a hemiplegic form of primary lateral sclerosis? J Neurol Neurosurg Psychiatry 1994;57:1280-1281.

11. Younger DS, Chou S, Hays AP, et al. Primary lateral sclerosis: a clinical diagnosis reemerges. Arch Neurol 1988;45:1304-1307.

12. Marti-Fabegras J, Pujol J. Selective involvement of the pyramidal tract on magnetic resonance imaging in primary lateral sclerosis. Neurology 1990;40:1799-1800. 